na E. M., Tuchin V. V., Khlebtsov N. G. Laser photothermolysis of biological tissues by using plasmonresonance particles // Quantum Electronics. 2008. Vol. 38, № 6. P. 536-542.

5. Labeau O., Tamarat P., Lounis B. Temperature dependence of the luminescence lifetime of single $\mathrm{CdSe} / \mathrm{ZnS}$ quantum dots // Physical Rev. Lett. 2003. Vol. 90, № 25. P. 257404-1-257404-4

6. Zhao Y. M., Riemersma C., Pietra F., Koole R., Doquenching of colloidal quantum dots // Acs Nano. 2012. Vol. 6, № 10. P. 9058-9067.

7. Maestro L. M., Rodriguez E. M., Rodriguez F. S., la Cruz M. C. I., Juarranz A., Naccache R., Vetrone F., Jaque D., Capobianco J. A., Sole J. G. CdSe quantum dots for two-photon fluorescence thermal imaging // Nano Lett. 2010. Vol. 10, № 12. P. 5109-5115.

8. Vossmeyer T., Katsikas L., Gienig M., Popovic I. G., Diesner K., Chemseddine A., Eychmiiller A. H. W. CdS nanoclusters : synthesis, characterization, size dependent oscillator strength, temperature shift of the excitonic transition energy, and reversible absorbance shift // J. Phys. Chem. 1994. Vol. 98, № 31. P. 7665-7673. nega C. D., Meijerink A. High-temperature luminescence

9. Yang J.-M., Yang H., Lin L. Quantum dot nano thermometers reveal heterogeneous local thermogenesis in living cells // Acs Nano. 2011. Vol. 5, № 6. P. 50675071.

10. Volkova E. K., Kochubey V. I., Konyukhova J. G., Skaptsov A. A., Galushka V. V., German S. V. Temperature dependence of the fluorescence spectrumof ZnCdS nanoparticles // Proc. SPIE. 2013. Vol. 8571. P. 85712P-1-85712P-6.

11. Пивен Н. Г., Щербак Л. П., Фейчук П. И., Калитчук С. М., Крылюк С. Г., Корбутяк Д. В. Термостимулированные эффекты синтеза нанокристаллов сульфида кадмия // Конденсированные среды и межфазные границы. 2006. Т. 8, № 4. С. 315-319.

12. Kochubey V. I., Volkova E. K., Konyukhova J. G. Glucose and temperature sensitive luminescence $\mathrm{ZnCdS}$ nanoparticles // Proc. SPIE. 2012. P. 85533B-85533B.

13. Моргунов Р. Б., Дмитриев А. И., Джардималиева Г. И., Помогайло А. Д., Розенберг А. С., Тапіmoto Y., Leonowicz M., Sowka E. Ферромагнитный резонанс кобальтовых наночастиц в полимерной оболочке // Физика твердого тела. 2007. Т. 49, № 8. C. $1436-1441$

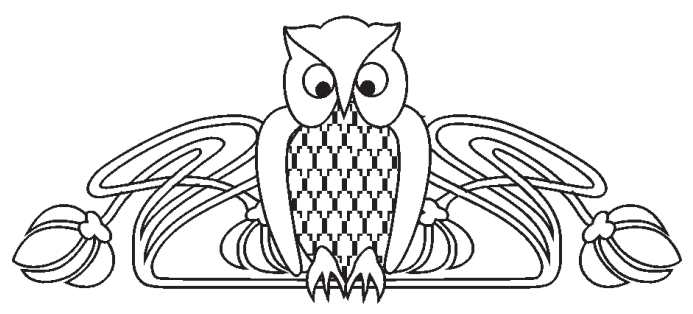

Саратовский государственный университет

${ }^{1}$ Московский государственный университет им. М. В. Ломоносова E-mail: Glukhiovskoy@gmail.com

В статье рассмотрено влияние вертикально ориентированного электрического поля на процесс формирования монослоев на поверхности воды и водных растворов неорганических солей. Экспериментально показано, что электрическое поле способно оказывать значительное влияние на формирование монослоев жирных кислот: на поверхности деионизованной воды происходит разрыхление монослоя, сформированного под влиянием поля, на поверхности водных растворов солей наблюдается уплотнение монослоя. Электрическое поле может быть существенным технологическим фактором в процессе формирования монослоев Ленгмюра.

Ключевые слова: ленгмюровский монослой, жирные кислоты, изотермы сжатия, поверхностное натяжение, ванна ЛенгмюраБлоджетт, заряженный монослой, ориентация молекул в электрическом поле.

\section{Langmuir Monolayers in the Electric Field}

\section{A. S. Chumakov, I. A. Gorbachev, A. V. Ermakov, V. P. Kim, E. G. Glukhovskoy}

An influence of the electric field oriented vertically on the formation process of monolayers. Water and water solutions of inorganic salts are used as a subphase. It's experimentally shown that the electric field may affect significantly on the monolayers formation of fatty acids: manolayr's loosening occurs when a deionized water is used as a subphase; manolayr's consolidation is observed when water solutions of inorganic salts are used as a subphase. An electric field can be significant technology factor of the Langmuir monolayer's formation process.

Key words: Langmuir monolayer, fatty acid, isotherm compression, surface tension, Langmuir-Blodgett trough, monolayer charged, the orientation of molecules in an electric field.

\section{Введение}

В настоящее время метод Ленгмюра-Блоджетт позволяет формировать мономолекулярные слои (так называемые ленгмюровские монослои (МС)) на границе раздела газ - жидкость и получать уникальные слоистые структуры, в которых каждый мономолекулярный слой может иметь свой собственный химический состав, кристаллическую структуру и ориентацию молекул $[1,2]$. 
Формирование монослоя и его структура зависят от многих факторов $[3,4]$. Одним из менее изученных факторов остается воздействие электрического поля. Обычно оно используется лишь при проведении исследований МС, например в методе скачка потенциала $[4,5]$. Влияние электрического поля на процессы, протекающие в ленгмюровской ванне, описывается в [6], но при этом поле направлено вдоль поверхности монослоя. Исследования, посвященные влиянию на МС электрического поля, направленного нормально к поверхности монослоя, найдены не были. В связи с этим целью настоящей работы является исследование влияния направления электрического поля на свойства МС, сформированного на поверхности воды и водных растворов солей $\mathrm{NiCl}_{2}$.

В деионизованной воде с кислотностью $\mathrm{pH}=7$ при $25^{\circ} \mathrm{C}$ концентрации ионов водорода $\left(\left[\mathrm{H}^{+}\right]\right)$и гидроксид-ионов $\left(\left[\mathrm{OH}^{-}\right]\right)$одинаковы и составляют $10^{-7}$ моль/л. Эти ионы будут разделяться и перераспределяться в электрическом поле. Аналогично на электрическое поле будут откликаться различные водные растворы неорганических солей [7]. При растворении неорганических солей и увеличении концентрации в растворе проводимость воды может меняться на несколько порядков. Аналогичные изменения происходят при постепенном растворении в ней моле- кул $\mathrm{CO}_{2}$, которые поступают из естественной атмосферы. При наложении электрического поля все эти процессы также необходимо учитывать. Еще более интересные и сложные процессы можно ожидать при формировании на поверхности воды монослоя амфифильного вещества или веществ, молекулы которых имеют большой дипольный момент. Такие молекулы будут откликаться на электрическое поле изменением своей ориентации, как это происходит в жидкокристаллических материалах. Таким образом, видно, что задача по изучению влияния электрического поля на формирование ленгмюровских монослоев довольно сложна.

Исследования влияния электрического поля проводились на двух моделях ленгмюровских ванн - KSV-Nima LBThrough Medium KN 1003 (KSV-Nima, Finland) и производства MDT-LB5 (NT-MDT, Россия). Для такого рода исследований была специально разработана система электродов и изменена конструкция барьеров. Барьеры были выполнены в виде нитей из диэлектрического гидрофобного материала (или проволок во фторопластовой оболочке), расположенных на поверхности жидкой субфазы под верхним электродом. Такие нити (или проволоки) натягивались на каркасы, расположенные и свободно перемещающиеся над верхним электродом (рис. 1) [8].

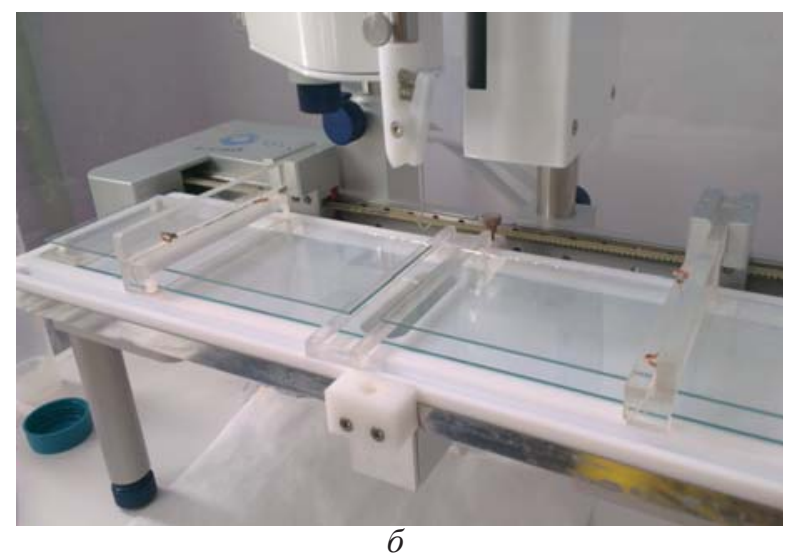

O

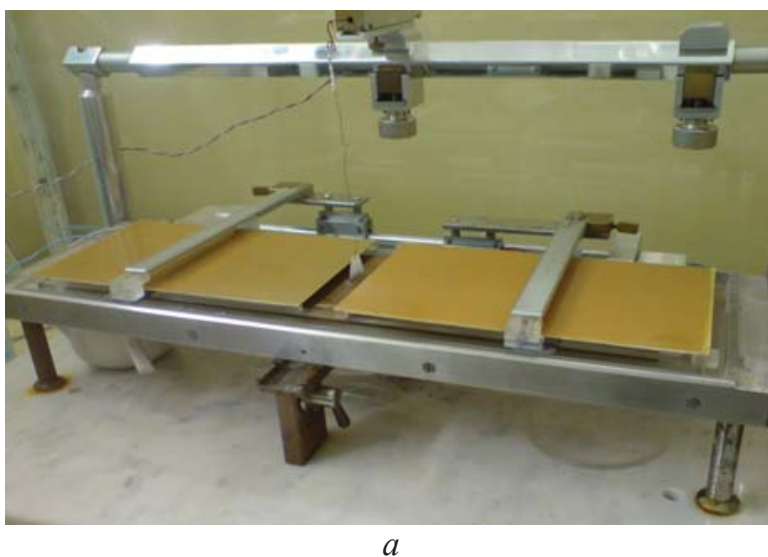

Рис. 1. Фотография установок с планарными электродами (a) и модифицированными барьерами (б)

В наших экспериментах варьировалось направление вектора напряженности - вверх или вниз, либо отсутствие электрических полей. Также проводились исследования МС на поверхности различных составов субфазы - на поверхности свежеприготовленной деионизованной воды и на поверхности водных растворов $\mathrm{NiCl}_{2}$.

\section{Результаты и их обсуждение}

В результате экспериментов были выявлены следующие факты:

1. (Arh-MC - деионизованная вода). Электрическое поле оказывает наиболее существенное влияние на формирование жидкоконденсированной (ЖК) фазы. Участок изотермы ЖК 
участка растягивается (примерно на 25\% и для «+/-» сверху - вниз) (рис. 2.), при приложении напряжения на электроды. Величина растяже- ния не столько зависит от направления вектора поля (вверх или вниз), сколько от самого факта наложения поля (есть или нет).

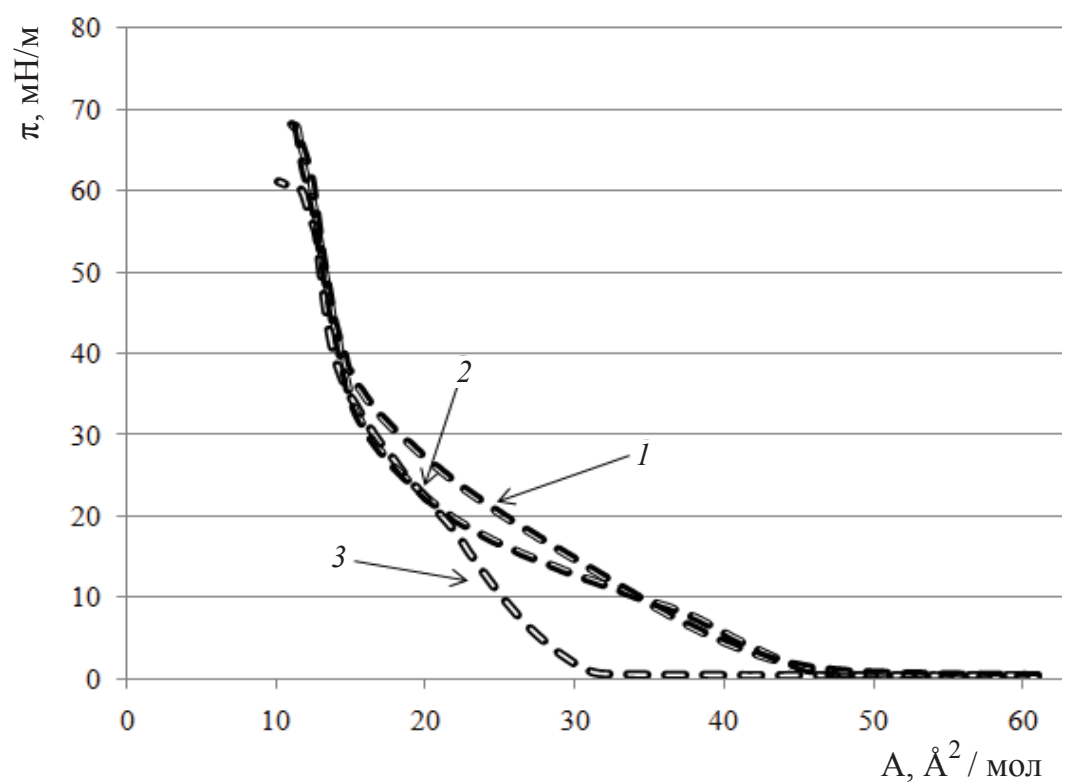

Рис. 2. Изотермы сжатия монослоя арахиновой кислоты на поверхности деионизованной воды под воздействием нормально приложенного электрического поля: 1 - вектор напряженности электрического поля направлен вниз; 2 - вектор напряженности электрического поля направлен вверх; 3 - электрическое поле отсутствует

2. Наблюдается различный характер растяжения. В случае, когда вектор напряженности электрического поля направлен вниз, зависимость $\pi$ - $A$ на ЖК участке имеет линейный характер, что типично для формирования ЖК фазы FA. В случае, когда вектор напряженности электрического поля направлен вверх, зависимость $\pi-A$ на ЖК участке имеет особую точку. Такое поведение характерно для систем типа МС молекул жидкого кристалла на поверхности воды (рис. 3).

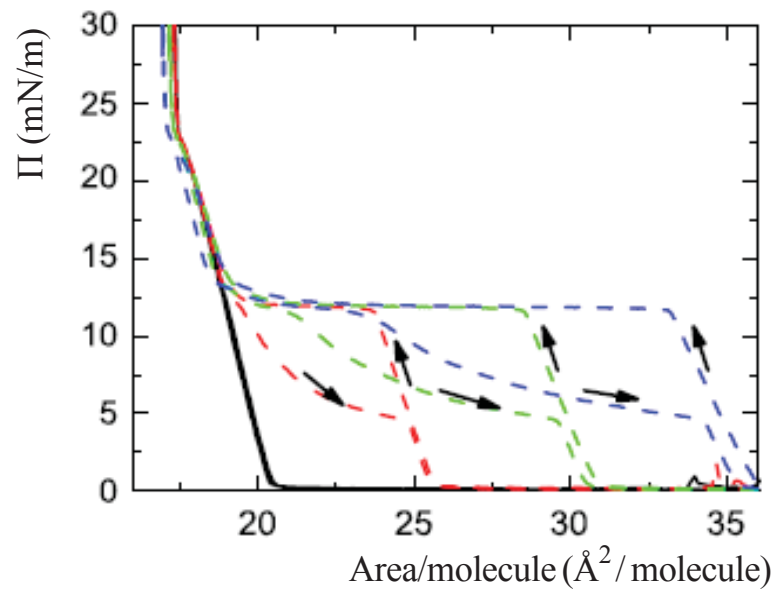

Рис. 3. Изотермы МС жидкокристаллического материала $8 \mathrm{CB}[9]$
Состояние справа от этой точки аналогично выстраиванию молекул в вертикальное состояние. Подъем же левее этой точки происходит с изменением крутизны, что может быть связано с двумя процессами: двумерной агрегацией молекул в состояние трехслойной структуры и/или формированием жидкорасширенного состояния.

Приложение электрического поля приводит к зарядке (положительно или отрицательно) приповерхностной области непосредственно под МС. При этом ионы $\mathrm{H}^{+}, \mathrm{OH}^{-}$встраиваются в пространство головных частей молекул монослоя, что приводит к «разрыхлению» последнего.

Сложнее интерпретируются процессы с растворами солей, в которых концентрация ионов металлов может отличаться от концентрации заряженных ионов воды на 4 и более порядков (например, если $\mathrm{C}_{\mathrm{Me}+}=10^{-3} \mathrm{M}$ и более, $\left.\mathrm{C}_{\mathrm{H}+, \mathrm{OH}-}=10^{-7} \mathrm{M}\right)$.

Так, при формировании МС на поверхности раствора $\mathrm{NiCl}_{2}$ наблюдаются, по сути, обратные эффекты, а именно: ЖК состояние в MC Arh формируется при достаточно сильном разряжении молекул на поверхности - при значении $A=0.55$ нм$^{2}$ (рис. 4). В то же время, как при приложении электрического поля, значение удельной площади для ЖК состояния становится заметно меньше. 


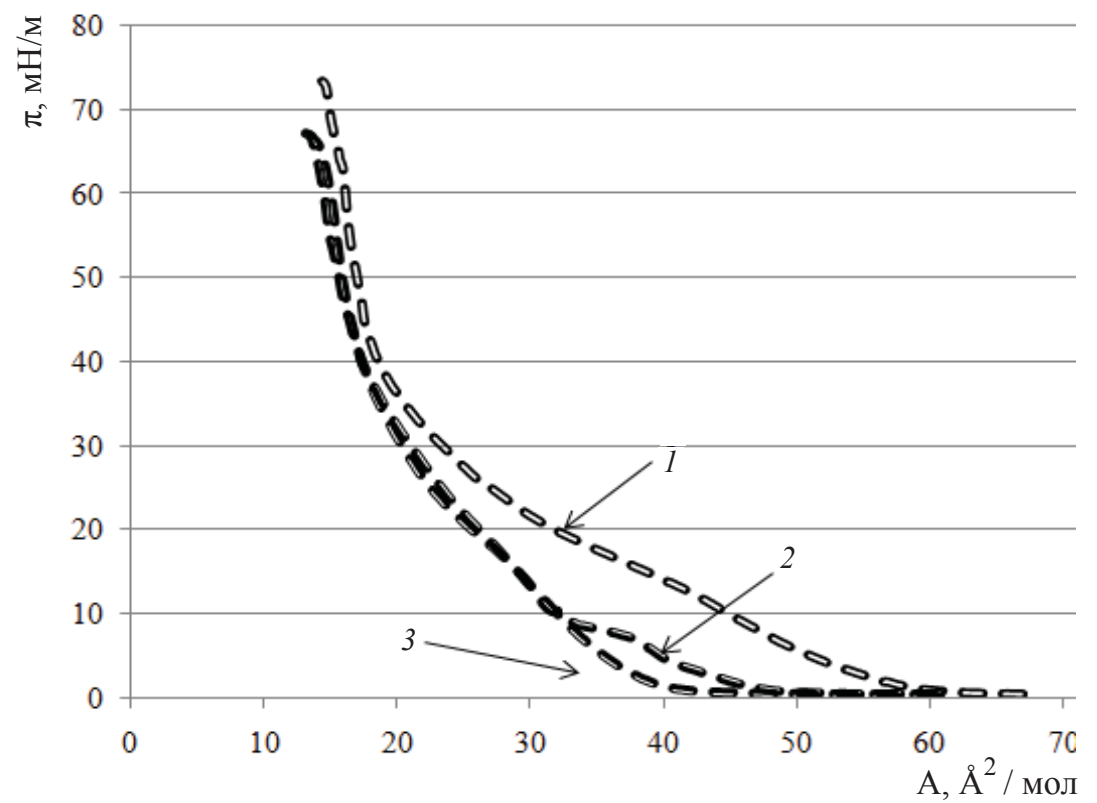

Рис. 4. Изотермы сжатия монослоя арахиновой кислоты на поверхности раствоpa $\mathrm{NiCl}_{2}$ под воздействием нормально приложенного электрического поля: 1 электрическое поле отсутствует; 2 - вектор напряженности электрического поля направлен вниз; 3 - вектор напряженности электрического поля направлен вверх

Возможно, часть ионов $\mathrm{OH}^{-}$вступает во взаимодействие с ионами $\mathrm{Ni}^{+2}$ (при приложении положительного потенциала к верхнему электроду) и препятствует протеканию реакции образования соли (арахината никеля), которая разрыхляет монослой без поля.

При другой полярности подтягиваются ионы $\mathrm{Cl}^{-}$, которые не взаимодействуют с монослоем, так как его нижняя часть итак заряжена отрицательно [4], а ионы $\mathrm{Ni}^{+2}$ уходят вниз, также блокируя образование соли.

\section{Заключение}

Таким образом, в ходе проведенного исследования было доказано, что электрическое поле способно оказывать значительное влияние на структуру ленгмюровских монослоев жирной кислоты. Причем наиболее ярко оно проявляется при формировании ЖК фазы монослоя, и, что характерно, для монослоев на поверхности деионизованной воды более важен сам факт наличия поля, но не его направление, а при использовании в качестве субфазы раствора соли происходят процессы, минимизирующие влияние ее ионов на формирование монослоя.

Работа выполнена при финансовой поддержке РФФИ (проект № 11-08-00529-а).

\section{Список литературы}

1. Chen $X$. Langmuir-Blodgett patterning : a bottom-up way to build mesostructures over large areas // Acc. Chem. Res. 2007. Vol. 40(6). P. 393-401.
2. Cindy Y., Huigao D., Fuke W. Enhanced ordering in gold nanoparticles self-assembly through excess free ligands // Langmuir. 2011. Vol. 27(7). P. 33553360 .

3. Motschmann H., Helmuth M. Langmuir-Blodgett films // Langmuir Blodgett Films. Handbook of Applied Colloid and Surface Chemistry / Max-PlanckInstitute of Colloids and Interfaces. Golm, Germany, 2001. P. 629-645.

4. Блинов Л.М. Ленгмюровские пленки // Успехи физических наук. 1988. Т. 155, вып. 3. С. 443-480.

5. Dynarowicz-Łatka P., Dhanabalan A., Oliveira Jr. O. N. Modern physicochemical research on Langmuir monolayers // Advances in Colloid and Interface Science. 2001. Vol. 91. P. 221-293.

6. Khomutov G. B., Gubin S. P., Khanin V. V. Formation of nanoparticles and one-dimensional nanostructures in floating and deposited Langmuir monolayers under applied electric and magnetic fields // Colloids and Surfaces : Physicochemical and Engineering Aspects. 2002. Vol. 198. P. 593-604.

7. $\ddot{E} с и д а$. Электроокисление в органической химии : пер. с англ. М. : Мир, 1987. 336 с.

8. Глуховской Е. Г., Брецезинский Г. Б., Горбачев И. А., Ким В. П., Гурьянов В. А. Установка для получения монослоев методом Ленгмюра-Блоджетт в электрическом поле : пат. 111297 Рос. Федерация. МПК GOINI3I02 / № 2011134887/28; заявл. 19.08.2011; опубл. 10.12.2011, Бюл. № 34.6 c.

9. Collins J., Funfschilling D., Dennin M. LangmuirBlodgett films of arachidic acid and nematic liquid crystals : characterization and use in homeotropic alignment // Thin Solid Films. 2006. Vol. 496. P. 601-605. 